\title{
RETROMOLAR CANAL - AN ESSENTIAL STRUCTURE THAT IS OFTEN FORGOTTEN
}

\author{
Magdalena Piskórz', Eliza Hamruk², Katarzyna Portka' ', Ingrid Różyło-Kalinowska' \\ 'Department of Dental and Maxillofacial Radiodiagnostics, Medical University of Lublin, Poland \\ ${ }^{2}$ Student Research Group at the Department of Dental and Maxillofacial Radiodiagnostics, Medical University of Lublin, Poland
}

\begin{abstract}
The retromolar canal is the anatomical branch of the mandibular canal. It contains a neurovascular bundle made of thin nerve fibers, veins and arteries surrounded by collagen fibers. The aim of the study was to review information about the retromolar canal presence and its consequences. The canal adjacent to the molar triangle may have different variants that occur at different frequencies. This canal constitutes $46.67 \%$ of all mandibular canal branches, making it the most common type of bifurcation, next to the canal branching upstream, buccal-lingual and to the tooth root. Thomas von Arx et al. classified variants of the alignment of the retromolar canal and distinguished five types. The retromolar canal and its content may be of great clinical importance for doctors in the area of the retromolar triangle. The retromolar nerve may contribute to inadequate anesthesia around the retromolar triangle, but this problem can be solved by techniques other than traditional anesthesia. Working in this area, doctors should take into account the possibility of damaging the neurovascular bundle. The analysis of the available literature show that the retromolar canal is not a rare phenomenon in the population. Therefore, should always be taken into account the possibility of its presence and consequences.
\end{abstract}

KEY WORDS: retromolar canal, retromolar foramen, cone beam computed tomography, panoramic radiographs, mandibular anatomy.

J Stoma 2021; 74, 1: 46-49

DOI: https://doi.org/10.5114/jos.2021.104698

\section{INTRODUCTION}

The retromolar canal is an anatomical branch of the mandibular canal, which according to the Naitoh is classified as type $\mathrm{F}$ [1]. The latest research proved that the retromolar canal constitutes $46.67 \%$ of all mandibular canal branches, making it the most common type of bifurcation, next to the canal branching upstream (40.00\%), buccal-lingual (2.86\%) and to the tooth root (10.48\%) [2]. The retromolar canal begins as a bifurcation of the bony wall of the mandibular canal and runs towards the retromolar triangle, which is limited by the temporal crest from the medial side, the anterior edge of the mandibular ramus from the lateral side and the distal surface of the mandibular third molar $[3,4]$. The retromolar canal contains a neurovascular bundle that is formed by thin myelin nerve fibers, veins and arterioles that are surrounded by collagen fibers along with a small amount of adipose tissue [5]. The nerve bundles running through the retromolar canal innervate the gingival mucosa of the lower premolars and molars [6]. There are also reports on the involvement of retromolar nerve in the innervation of the area of the retromolar triangle, the pulp of third molar, a part of the cheek mucosa and the temporal muscles [5]. Haas et al. [6] report that an abnormal branch for the buccal muscle

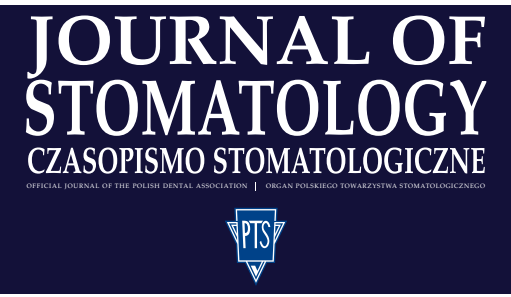

AdDRESS FOR CORRESPONDENCE: Magdalena Piskórz, Department of Dental and Maxillofacial Radiodiagnostics, Medical University of Lublin, 6 Dr Witolda Chodźki St., 20-093 Lublin, Poland, e-mail:mkrzyzanowska86@gmail.com ReCEIVED: 17.12.2020 • ACCEPTED: 08.01.2021 • Published: 30.03.2021 
(called the abnormal buccal nerve) can run through the retromolar canal. In some cases, damage to the neurovascular bundle may lead to complications in the form of hemorrhages, sensory disturbances and traumatic neuromas, which may occur following surgical removal of third molars, peroneal osteotomy or during mandibular nerve anesthesia [6-8]. Unfortunately, this structure is often overlooked in the textbooks that future adepts of dentistry learn from.

The aim of the study was to review information about the retromolar canal presence and its consequences.

The scientific literature in the PubMed database was reviewed. The articles associated with the entry "retromolar canal" were analyzed. Due to repeated information in numerous articles, only 32 articles were considered in this paper.

\section{DISCUSSION}

The observation of a small and variable in terms of structure and course of the retromolar canal was possible thanks to the intensive development of imaging studies, especially computed tomography (CT) and cone beam computed tomography (CBCT) [9]. In some patients, the retromolar canal is already visible on the panoramic image, although this technique reveals only small percentage of the retromolar canals [10]. The tomography with a slightly higher radiation dose provides the possibility of assessing the jaw bone structures in three dimensions, which was not possible with the two-dimensional technique. On the other hand, compared to another three-dimensional technique - CT - CBCT allows for a precise examination with a lower single dose of radiation $[5,11,12]$. There are reports off the use of high-resolution magnetic resonance imaging to examine the mandibles of living patients and the endoscopic technique for imaging the course of the retromolar canal on "dry" cadaver mandibles [13-15]. Ikeda et al. [16] revealed that multiplanar MR imaging show excellent anatomic detail in the mandibular canal. Therefore, this imaging modality can be taking into account apart from CBCT and CT during finding anatomical variety of mandibular canal. There was a great individual variability in the course, diameter and length of the canal in mandibles. Sometimes there course of the retromolar canal is bent. Moreover, in some cases, the main canal produces its own branches. Due to the availability of accurate imaging techniques, it has become possible to analyze the course of the retromolar canal. Tomas von Arx et al. [17] classified variants of the alignment of the retromolar canal and distinguished five types:

- type A1 - vertical course of the retromolar canal (Figures 1 and 2),

- type A2 - vertical course of the retromolar canal with a horizontal branch,

- type B1 - bent course of the retromolar canal (Figure 3),
- type B2 - bent course of the retromolar canal with an additional horizontal branch,

- type C - horizontal course of the retromolar canal.

According to research carried out by von Arx in 2005 type A1 was found in $20.7 \%$ of the patients, type A2 was $8.6 \%$ of the examined people, type B1 - 37.9\%, type B2 was found in $13.8 \%$, and $19 \%$ were classified as type C [18]. Based on the available mandibles, Motamedi et al. [19] estimated the average diameter of the retromolar nerve at $1.7 \mathrm{~mm}$ (range from 1.1 to $2.1 \mathrm{~mm}$ ): in women this value was on average $1.5 \mathrm{~mm}$, and in men $1.8 \mathrm{~mm}$. Kim et al. [20] examined the contents of the retromolar canal. They found that the average area of the neurovascular bundle was $0.59 \mathrm{~mm}^{2}$, and the areas of the artery and nerve, respectively were 0.07 and $0.05 \mathrm{~mm}^{2}$. Studies on the presence of the retromolar canal have been conducted in various populations. CBCT studies of living adults, cadaver mandibles and the "dry" mandibles were analyzed. A lot of researchers have attempted to determine the frequency of the retromolar canal in the populations. They obtained different results: from the frequency of $1.7 \%$ (Ossenberg) to $75.4 \%$ (Patil et al.). Such diverse results were obtained due to the use of diagnostic techniques: CBCT, panoramic radiography and anatomical examinations on dry, macerated mandibles [5, 10, 21-27]. As stated in the studies by Haas et al. [6], the effectiveness of CBCT and CT in detecting the retromolar canal is almost four times higher than in the case of panoramic radiography.

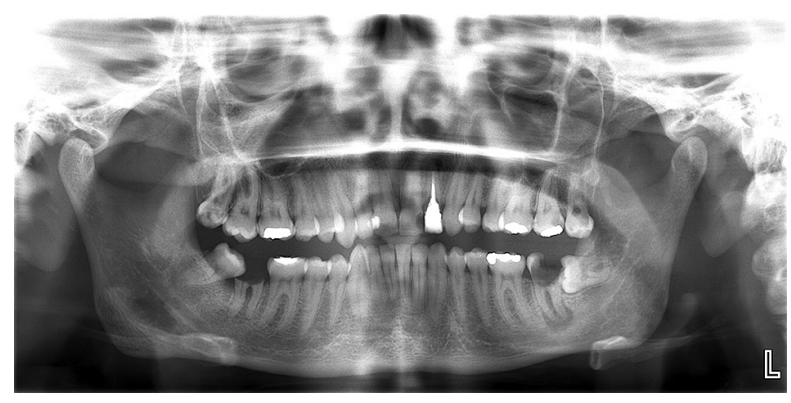

FIGURE 1. Panoramic X-ray presents type A1 of retromolar canal on the right side

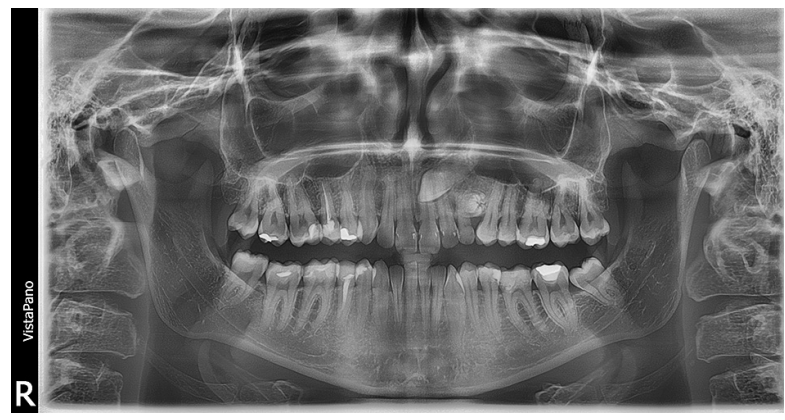

FIGURE 2. Panoramic X-ray presents type A1 of retromolar canal on the left side 

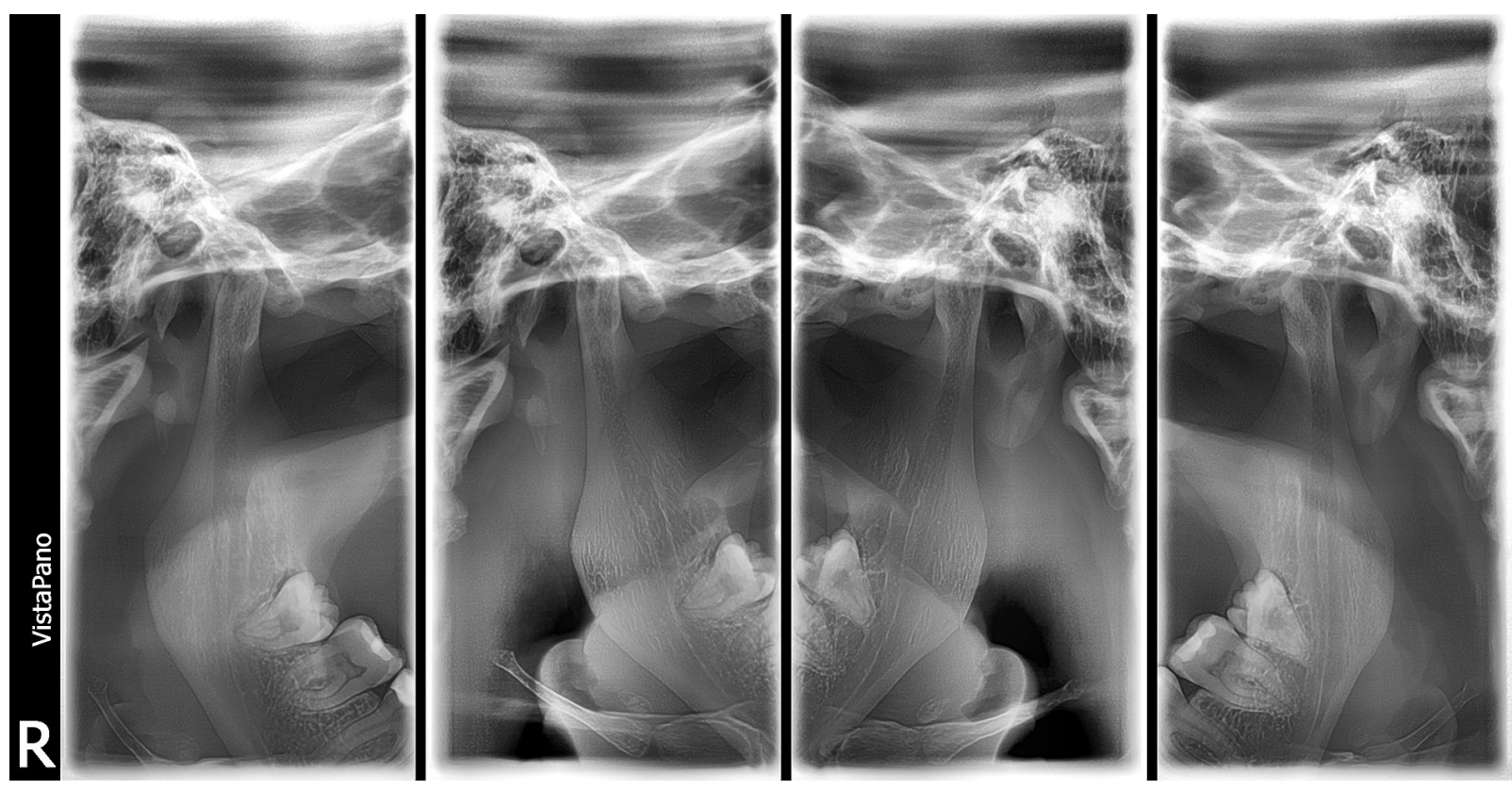

FIGURE 3. Double lateral temporomandibular joint disorder projection presents type B1 of retromolar canal on the left side

However, there were no significant differences in the incidence of the apical canal between females and males [5]. Some studies suggest that one side may be more often characterized by the presence of the retromolar canal, while other researchers have obtained results indicating that there is no such relationship and there is no significant difference in frequency between the sides of the mandible $[5,13]$. There are reports that the highest occurrence of the retromolar canal is observed in the group adolescents [12].

The retromolar canal may be of great clinical importance for clinicians working in the area of the retromolar triangle. The presence of the retromolar canal, may cause incomplete anesthesia in the retromolar triangle. Then the expected effect can be achieved by injecting a few drops of anesthetic in the area of the retromolar triangle. In the case of the retromolar canal it may be necessary to use the Gow-Gates technique or the Akinosi-Vazirani technique $[3,12,28,29]$. The Gow-Gates mandibular block technique is based on anesthesia of the inferior alveolar nerve by administering the anesthetic to the area of the mandibular nerve from one puncture on the lateroanterior surface of the condyle. The injection site is determined by a developed mathematical algorithm. This algorithm allows to deposit the anesthetic in a very safe and very effective way [30]. The Akinosi-Vazirani technique for mandibular anesthesia is performed with the mouth closed. It can be used in all patients, but it is indicated in patients with trismus and problems with opening the mouth [31].

When performing surgical procedures, such as extraction of third molars, autologous bone grafting, orthognathic surgery or harvesting of a mucoperiosteal flap, the retromolar neurovascular bundle may be damaged and its injury may cause complications. These complications include excessive bleeding, sensory disturbances, formation of a hematoma, traumatic neuroma or bruising. Temporal paresis may also occur if the neurovascular bundle running through the retromolar canal has fibers aimed at this muscle $[3,5,8,12,18,29,32]$. The retromolar canal is a space where cancer and infection can potentially spread [12]. In prosthetically treated patients, the presence of the retromolar nerve may cause problems in the use of dentures and even difficulties in implanting dental implants $[3,33]$.

\section{CONCLUSIONS}

The analysis of the available literature show that the retromolar canal is not a rare phenomenon in the population. Therefore, doctors should always be taken into account possibility of its presence and consequences.

\section{CONFLICT OF INTEREST}

The authors declare no potential conflicts of interest with respect to the research, authorship, and/or publication of this article.

\section{References}

1. Okumus O, Dumlu A. Prevalence of bifid mandibular canal according to gender, type and side. J Dent Sci 2019; 14: 126-133.

2. Zhou X, Gao X, Zhang J. Bifid mandibular canals CBCT assessment and macroscopic observation. Surg Radiol Anat 2020; 42 1073-1079. 
3. Malik S, Sunita, Choudhary A. Clinical and anatomical study of retromolar foramen on adult dry mandible in Uttarakhand region in India. Int J Cur Res Rev 2018; 10: 5-7.

4. Kumar Potu B, Kumar V, Salem AH, Abu-Hijleh M. Occurrence of the retromolar foramen in dry mandibles of south-eastern part of India: a morphological study with review of the literature. Anat Res Int 2014; 2014: 296717. DOI: https://doi.org/10.1155/ 2014/296717.

5. Tassoker M, Sener S. Investigation of the prevalence of retromolar canals: a cone beam CT study. Int J Morphol 2017; 35: 1298-1302.

6. Haas LF, Dutra K, Porporatti AL et al. Anatomical variations of mandibular canal detected by panoramic radiography and CT: a systematic review and meta-analysis. Dentomaxillofac Radiol 2016; 45: 20150310. DOI: 10.1259/dmfr.20150310.

7. Filo K, Schneider T, Kruse AL, Locher M, Gratz KW, Lubbers HT. Frequency and anatomy of the retromolar canal - implications for the dental practice. Swiss Dent J 2015; 125: 278-292.

8. Jamalpour M, Shokri A, Falah-Koshki S, Zavareian A. Evaluation of retromolar canals with cone beam-computed tomography in an Iranian adult population: a retrospective study. Int J Clin Dent 2016; 9: 233-240.

9. Nithya J, Aswath N. Assessing the prevalence and morphological characteristic of bifid mandibular canal using cone-beam computed tomography - a retrospective cross-sectional study. J Clin Imaging Sci 2020; 10: 30. DOI: 10.25259/JCIS_67_2019.

10. Muinelo-Lorenzo J, Suarez-Quintanilla JA, Fernandez-Alonso A, Marsillas-Rascado S, Suarez-Cunqueiro MM. Descriptive study of the bifid mandibular canals and retromolar foramina: cone beam CT vs panoramic radiography. Dentomaxillofac Radiol 2014; 43: 20140090. DOI: 10.1259/dmfr.20140090.

11. Truong MK, He P, Adeeb N, Oskouian RJ, Tubbs RS, Iwanaga J. Clinical anatomy and significance of the retromolar foramina and their canals: a literature review. Cureus 2017; 9: 1781. DOI: 10.7759/cureus.1781.

12. Park MK, Jung W, Bae JH, Kwak HH. Anatomical and radiographic study of the mandibular retromolar canal. J Dent Sci 2016; 11: 370-376

13. Wamasing P, Deepho C, Watanabe H, Hayashi Y, Sakamoto J, Kurabayashi T. Imaging the bifid mandibular canal using high resolution MRI. Dentomaxillofac Radiol 2019; 48: 20180305. DOI 10.1259/dmfr.20180305.

14. Deepho C, Watanabe H, Kotaki S, Sakamoto J, Sumi Y, Kurabayash T. Utility of fusion volumetric images from computed tomography and magnetic resonance imaging for localizing the mandibular canal. Dentomaxillofac Radiol 2017; 46: 20160383. DOI: 10.1259/ dmfr.20160383.

15. Iwanaga J, Watanabe K, Tsuyoshi S, et al. A novel method for observation of the mandibular foramen: application to a better understanding of dental anatomy. Anat Rec (Hoboken) 2017; 300: 1875-1880. DOI: 10.1002/ar.23639.

16. Ikeda K, Ho KC, Nowicki BH, Haughton VM. Multiplanar MR and anatomic study of the mandibular canal. AJNR Am J Neuroradiol 1999; 17: 579-584.

17. Von Arx T, Hänni A, Sendi P, Buser D, Bornstein MM. Radiographic study of the mandibular retromolar canal: an anatomic structure with clinical importance. J Endod 2011; 37: 1630-1635.

18. Malusare P, Navalkar A, Das D, Soman BP, Sali S. Assessing the incidence and course of mandibular retromolar canal using cone beam computed tomography in Indian sub-population - a retrospective study. EC Dent Sci 2018; 17: 1479-1484.

19. Motamedi MHK, Gharedaghi J, Mehralizadeh S, et al. Antropomorphic assessment of the retromolar foramen and retromolar nerve: anomaly or variation of normal anatomy? Int J Oral Maxillofac Surg 2016; 45: 241-244.

20. Kim HJ, Kang H, Seo YS, Kim DK, Yu SK. Anatomic evaluation of the retromolar canal by histologic and radiologic analyses. Arch Oral Biol 2017; 81: 192-197.

21. Alves N, Deana NF. Anatomical and radiographical study of the retromolar canal and retromolar foramen in macerated mandibles. Int J Clin Exp Med 2015; 8: 4292-4296.
22. Fuentes R, Arias A, Farfan C, et al. Morphological variations of the mandibular canal in digital panoramic radiographs: a retrospective study in a Chilean population. Folia Morphol 2019; 78: 163-170.

23. Kang JH, Lee KS, Oh MG, et al. The incidence and configuration of the bifid mandibular canal in Koreans by using cone-beam computed tomography. Imaging Sci Dent 2014; 44: 53-60.

24. Sidorenko Capote T, Goncalves MA, Duarte Bonini Campos JA. Retromolar canal associated with age, side, sex, bifid mandibular canal and accessory mental foramen in panoramic radiographs of Brazilians. Anat Res Int 2015; 2015: 434083. DOI: 10.1155/ 2015/434083.

25. Nikkerdar N, Golshah A, Norouzi M, Falash-Kooshki S. Incidence and anatomical prosperities of retromolar canal in an Iranian population: a cone beam computed tomography study. Int J Dent 2020; 2020: 9178973. DOI: 10.1155/2020/9178973.

26. Zhang YQ, Zhao YN, Liu DG, Meng Y, Ma XC. Bifid variations of the mandibular canal: cone beam computed tomography evaluation of 1000 Northern Chinese patients. Oral Surg Oral Med Oral Pathol Oral Radiol 2018; 126: 271-278.

27. Gamieldien MY, Van Schoor A. Retromolar foramen: an anatomical study with clinical considerations. Br J Oral Maxillofac Surg 2016; 54: 784-787.

28. Filo K, Schneider T, Kruse AL, Locher M, Gratz KW, Lubbers HT. Frequency and anatomy of the retromolar canal - implications for the dental practice. Swiss Dent J 2015; 125: 278-292.

29. Haas DA. Alternative mandibular nerve block techniques: a review of the Gow-Gates and Akinosi-Vazirani closed-mouth mandibular nerve block techniques. J Am Dent Assoc 2011; 142: 85-125.

30. Gow-Gates G, Watson JE. Gow-Gates mandibular block - applied anatomy and histology. Anesth Prog 1989; 36: 193-195.

31. Ravi Kiran BS, Kashyap VM, Uppada UK, Tiwari P, Mishra A, Sachdeva A. Comparison of efficacy of Halstead, Vazirani Akinosi and Gow Gates techniques for mandibular anesthesia. J Maxillofac Oral Surg 2018; 17: 570-575.

32. Di Bari R, Coronelli R, Cicconetti A. An anatomical radiographic evaluation of the posterior portion of the mandible in relation to autologous bone harvest procedures. J Craniofac Surg 2014; 25: 475-483.

33. Patil S, Matsuda Y, Nakajima K, Araki K, Okano T. Retromolar canals as observed on cone-beam computed tomography: their incidence, course and characteristics. Oral Surg Oral Med Oral Pathol Oral Radiol 2013; 115: 692-699. 